\title{
A New FuZzy Logic BASEd SPACE Vector MODULATION APPROACH ON DIRECT TORQUE CONTROLLED INDUCTION MOTORS
}

\author{
Fatih Korkmaz, İsmail Topaloğlu and Hayati Mamur \\ Department of Electrical and Electronics Engineering \\ Çankırı Karatekin University, 18200, Çankırı, TURKEY \\ fkorkmaz@karatekin.edu.tr
}

\begin{abstract}
The induction motors are indispensable motor types for industrial applications due to its wellknown advantages. Therefore, many kind of control scheme are proposed for induction motors over the past years and direct torque control has gained great importance inside of them due to fast dynamic torque response behavior and simple control structure. This paper suggests a new approach on the direct torque controlled induction motors, Fuzzy logic based space vector modulation, to overcome disadvantages of conventional direct torque control like high torque ripple. In the proposed approach, optimum switching states are calculated by fuzzy logic controller and applied by space vector pulse width modulator to voltage source inverter. In order to test and compare the proposed DTC scheme with conventional DTC scheme simulations, in Matlab/Simulink, have been carried out in different speed and load conditions. The simulation results showed that a significant improvement in the dynamic torque and speed responses when compared to the conventional DTC scheme.
\end{abstract}

\section{KEYWORDS}

Direct torque control, Fuzzy logic control, Space vector modulation, Induction motor control,

\section{INTRODUCTION}

In electromechanic systems, Direct torque control (DTC) of induction motor is well-known control scheme which provides fast dynamic response compared with other control schemes like field oriented control (FOC). DTC has been proposed for induction motor control in 1985 by Takahashi [1] and similar idea that the name of Direct Self Control devoloped in 1988 by Depenbrock [2].

Over the past years, DTC has gained great attention due to its advantages like simple structure, robustness to parameters variations, fast dynamic response, not need to current regulators...etc. However, like every control scheme, DTC has some disadvantages too. If we want to sort out some of these disadvantages; difficulty to control torque and flux at very low speed, high current and torque ripples, variable switching frequency behavior and high sampling frequency needed for digital implementation.

In order the overcome these disadvantages many researchers have been researching on the DTC drive and they can grouped under several headings:

Sundarapandian et al. (Eds) : ICAITA, SAI, SEAS, CDKP, CMCA-2013

pp. 161-169, 2013. (C) CS \& IT-CSCP 2013

DOI : $10.5121 / \mathrm{csit} .2013 .3813$ 
- Using different switching techniques and inverter topologies [3-7]

- Using artificial intelligence on different sections of system [8-9]

- Using different observer models [10-11]

In this paper, a new fuzzy logic based space vector modulation method has been proposed to improve torque behavior of induction motor on the DTC scheme. The fuzzy logic controller in the proposed method rates of flux and torque errors and describes optimum space vector to minimize flux and torque errors. The experimantal studies have performed with dSPACE 1103 controller board to performance testing of the proposed control method. . In Section II of this paper, the basic principles of DTC has shortly introduced and in Section III, detailed information about the proposed method has presented. Section IV presents the experimental results of the the proposed method. Finally, conclusion has given in Section V.

\section{DIRECT TORQUE CONTROL}

In conventional DTC scheme, the control of an induction motor involves the direct control of stator flux vector by applying optimum voltage switching vectors of the inverter. For this control, the stator current should be decoupled two independent components as flux and torque components like dc motors. The clarke transformation method is uses in this decoupling process in the DTC scheme.

The DTC bases on the selection of the optimum voltage vector which makes the flux vector rotate and produce the demanded torque. In this rotation, the amplitude of the stator flux vector remains in hysteresis band limits[12]. Stator flux linkage vector is estimated using (8)-(10).

$$
\begin{aligned}
& \lambda_{\alpha}=\int\left(V_{\alpha}-R_{s} i_{\alpha}\right) d t, \\
& \lambda_{\beta}=\int\left(V_{\beta}-R_{s} i_{\beta}\right) d t, \\
& \lambda=\sqrt{\lambda_{\alpha}^{2}+\lambda_{\beta}^{2}} .
\end{aligned}
$$

Where $\lambda$ is stator flux vector, $v_{\alpha}$ and $v_{\beta}$ stator voltages two phase components, $i_{\alpha}$ and $i_{\beta}$ line currents in $\alpha-\beta$ reference frame and $R_{s}$ describes stator resistance. The electromagnetic torque of the induction machine can be calculated as given in Eq. 7

$$
T_{e}=\frac{3}{2} p\left(\lambda_{\alpha} i_{\beta}-\lambda_{\beta} i_{\alpha}\right)
$$

Where, $\mathrm{p}$ is the number of pole pairs. In DTC scheme, stator flux rotate trajectory devided six region and well- defined of stator flux region is directly affects on control performance and calculation of stator flux vector region as given in Eq. 8 .

$$
\theta_{\lambda}=\tan ^{-1}\left(\frac{\lambda_{\beta}}{\lambda_{\alpha}}\right)
$$

These estimated values are compared to reference values and the resultant errors are applied to the hysteresis comparators. Two different hysteresis comparators, as flux and torque comparators, generate other control parameters on the DTC scheme. Flux hysteresis comparator is two level type while torque comparator is tree level type. According to the hysteresis comparators outputs, 
the estimated angle of flux linkage and using a switching table, optimum voltage vectors are selected and applied to the inverter. The basic schematic representation of DTC scheme for an induction motor is shown in Figure 1.

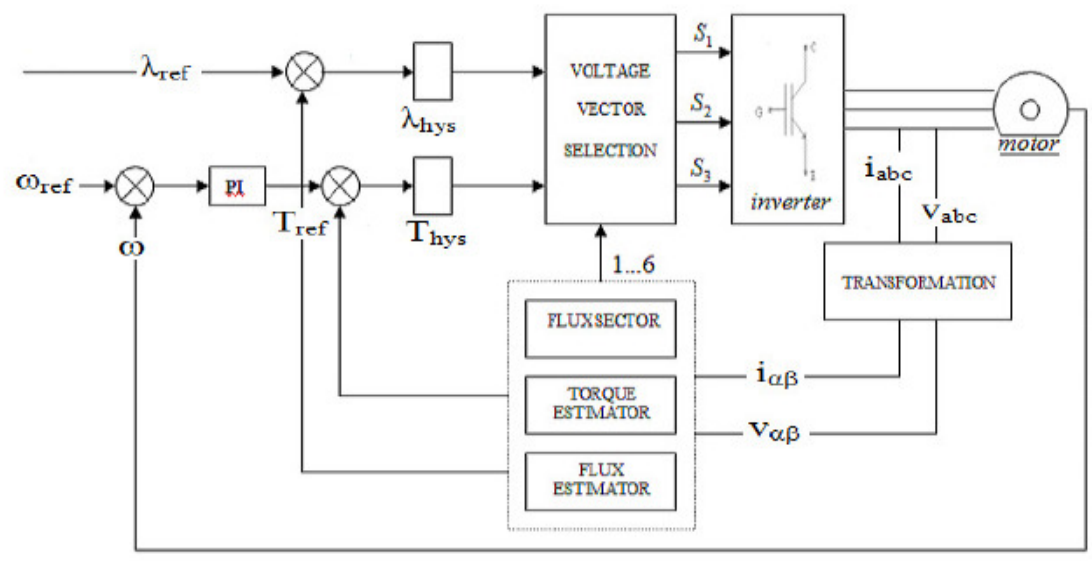

Figure 1. Conventional DTC scheme

\section{THE FUZZY BASED SVM-DTC}

The objective of space vector pulse width modulation technique is to obtain the demanded output voltage, Uout, by instantaneously combination of the switching states corresponding the basic space vectors (Figure 2.)[13].

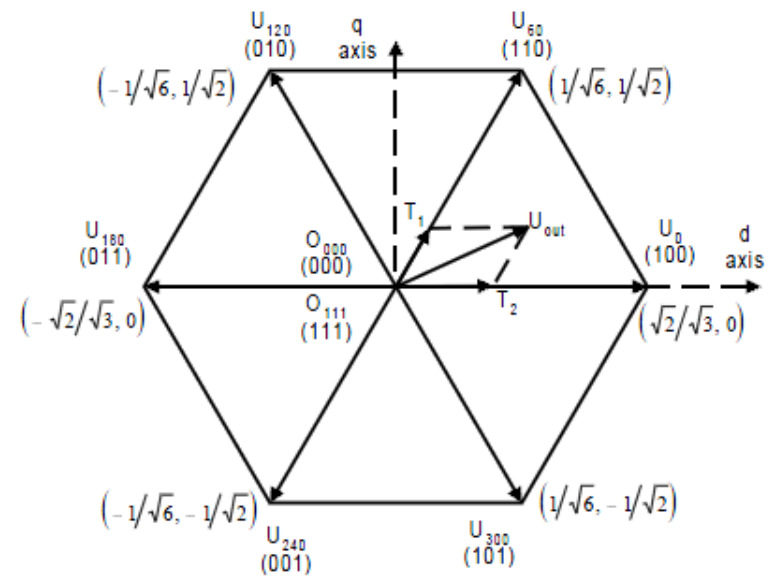

Figure 2. Basic space vectors

$U_{\text {out }}$ can be obtained as Eq. 6. by applying the inverter in switching states $U_{x}$ and $U_{x+60}$ or $U_{x-60}$ for the time periods, $T_{1}$ and $T_{2}$ periods of time respectively.

$U_{\text {out }}(n T)=\frac{1}{T}\left(T_{1} U_{x}+T_{2} U_{x \pm 60}\right)$ 
It must be pointed out that the sum of $T_{1}$ and $T_{2}$ periods should be less than or equal to total sampling time period, $\mathrm{T}$. If $T_{1}+T_{2}\langle T$, than the inverter needs to be in pasive vectors, $0_{000}$ or $0_{111}$ states, for the rest of the total time period that pasive time period can be named $T_{0}$. Thus, the calculation of total time period is given in Eq. 7 .

$T_{1}+T_{2}+T_{0}=T$

Therefore, Eq. 6 becomes Eq. 7 in the following,

$T U_{\text {out }}=T_{1} U_{x}+T_{2} U_{x \pm 60}+T_{0}\left(0_{000}\right.$ or $\left.0_{111}\right)$

From Eq. 8., we get Eq. 9. for $T_{1}$ and $T_{2}$.

$\left[\begin{array}{ll}T_{1} & T_{2}\end{array}\right]^{\tau}=T\left[\begin{array}{ll}U_{x} & U_{x \pm 60}\end{array}\right]^{-1} U_{\text {out }}$

where $\left[\begin{array}{ll}U_{x} & U_{x \pm 60}\end{array}\right]^{-1}$ is the normalized decomposition matrix for the sector.

Assume the angle between $U_{\text {out }}$ and $U_{x}$ is $\alpha$ from Figure 3, it can be also obtained Eq. 10. and Eq. 11. for the $T_{1}$ and $T_{2}$ [13].

$$
\begin{aligned}
& T_{1}=\sqrt{2} T\left\|U_{\text {out }}\right\| \cos \left(\alpha+30^{\circ}\right) \\
& T_{2}=\sqrt{2} T\left\|U_{\text {out }}\right\| \sin (\alpha)
\end{aligned}
$$

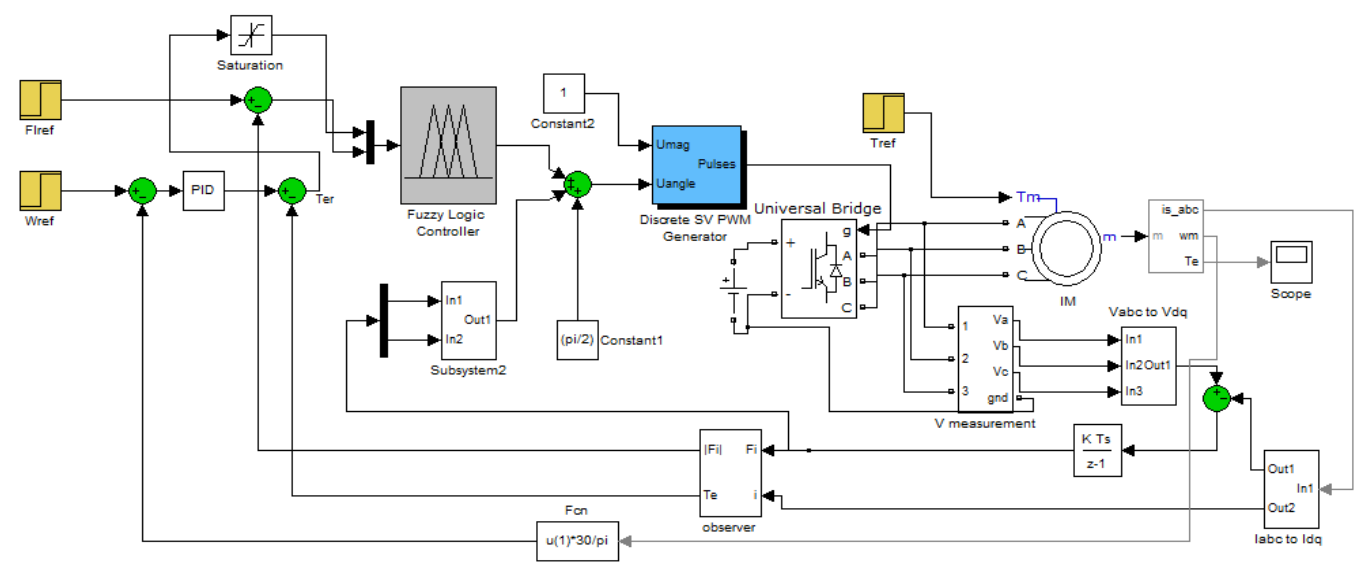

Figure 3. The Simulink block diagram the proposed scheme

The proposed fuzzy based SVM-DTC scheme includes a fuzzy logic controller to produce optimum control vector. The optimum control vector angle is calculated by fuzzy logic controller with instantaneously flux and torque errors. On this calculation, fuzzy logic rates both errors and produces necessary change in vector angle for next step. Then, calculated optimum vector angle applied to discrete space vector pulse width modulation block (DSV-PWM) and DSV-PWM generates switching signals. The Simulink block diagram of the proposed system is given in Figure 3 . 
The membership functions of fuzzy logic controller flux-torque inputs and angle output can be seen in Figure 4. Table 1. describes rule table of fuzzy logic controller.

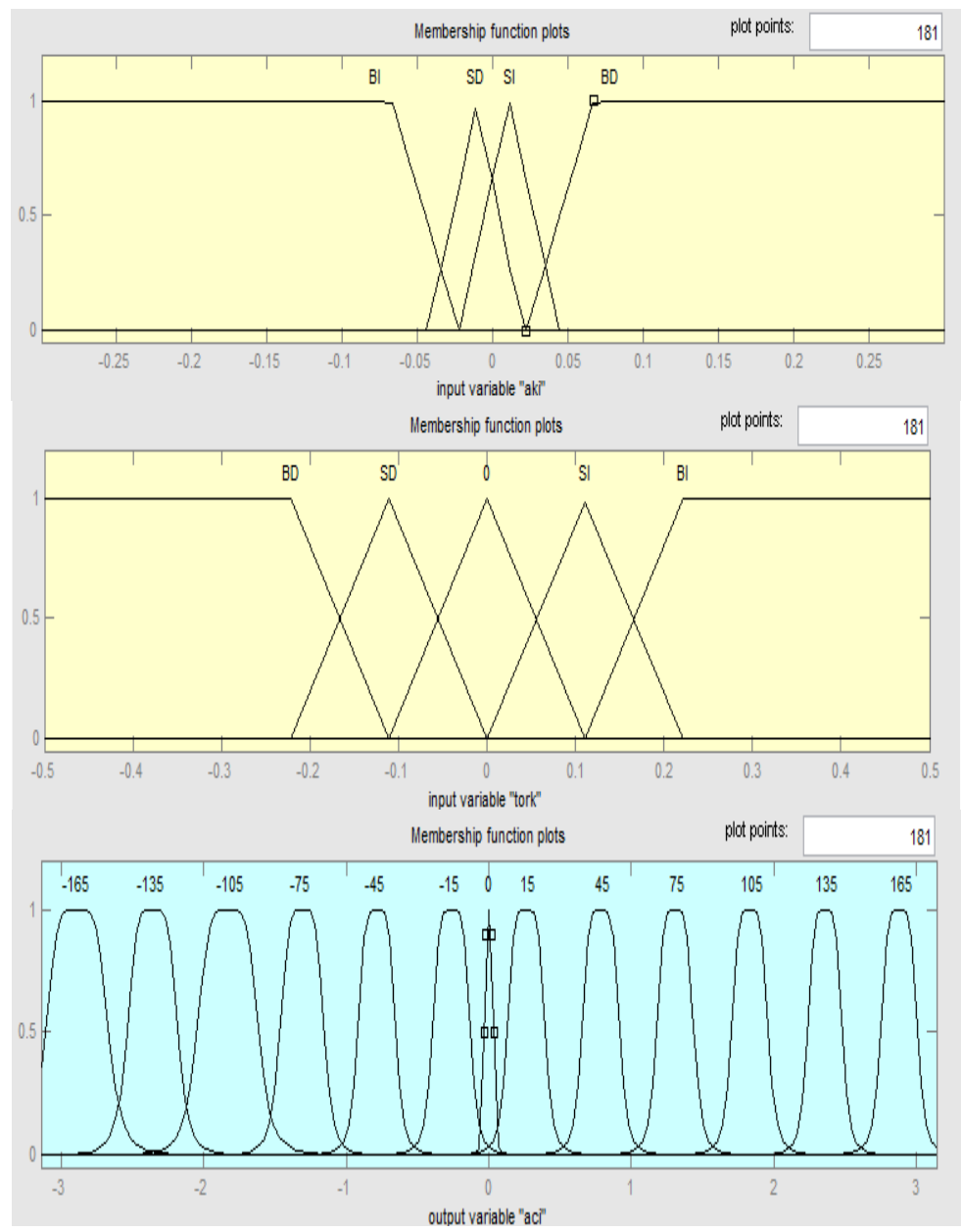

Figure 4. Flux, torque and angle membership functions

Table 1. Rule table of fuzzy logic controller

\begin{tabular}{|c|c|c|c|c|c|}
\hline \multirow{2}{*}{\multicolumn{2}{|c|}{ Rules }} & \multicolumn{4}{|c|}{ Flux } \\
\hline & & BD & SD & SI & BI \\
\hline \multirow{5}{*}{$\begin{array}{l}\mathscr{\sigma} \\
\stackrel{0}{0} \\
\dot{\theta}\end{array}$} & BD & -135 & -105 & -75 & -45 \\
\hline & SD & -165 & -135 & -45 & -15 \\
\hline & 0 & 0 & 0 & 0 & 0 \\
\hline & SI & 165 & 135 & 45 & 15 \\
\hline & BI & 135 & 105 & 75 & 45 \\
\hline
\end{tabular}




\section{Simulations}

In order to evaluate the effectiveness of the proposed fuzzy logic based SVM-DTC method simulation works have been carried out in Matlab/Simulink software. The DTC scheme and the induction machine used in the simulation works have the parameters given in Table 2.

Table 2. Induction Machine and Simulation parameters

\begin{tabular}{|c|c|}
\hline \multicolumn{2}{|c|}{ IM and Simulation Parameters } \\
\hline Inverter bus voltage $(\mathrm{V})$ & $400 \mathrm{~V}$ \\
\hline Rated Power $(\mathrm{kW})$ & 4 \\
\hline Stator resistance $(\Omega)$ & 1.405 \\
\hline Stator inductance $(\mathrm{H})$ & 0.0058 \\
\hline Pole pairs & 2 \\
\hline Sampling time $(\mu \mathrm{s})$ & 50 \\
\hline Flux reference $(\mathrm{Wb})$ & 0.8 \\
\hline
\end{tabular}

Some tests have been carried out to compare the performances of the proposed fuzzy logic based dSV-PWM DTC (FL-dSV-PWM) with conventional DTC (C-DTC). In order to compare the performances with the C-DTC and the proposed FLSVM-DTC on induction motor drive different speed and load range applied to the induction motor. The dynamic performances of the schemes are performed by applying step change on load, $0 \mathrm{Nm}$ to $10 \mathrm{Nm}$, at 0,5 . sec.

In first step of the simulation studies, the induction motor has been tested at rated speed with two different load conditions. The simulation results of speed and torque responses at $1500 \mathrm{rpm}$ reference are shown in Figure 5. and Figure 6., respectively.

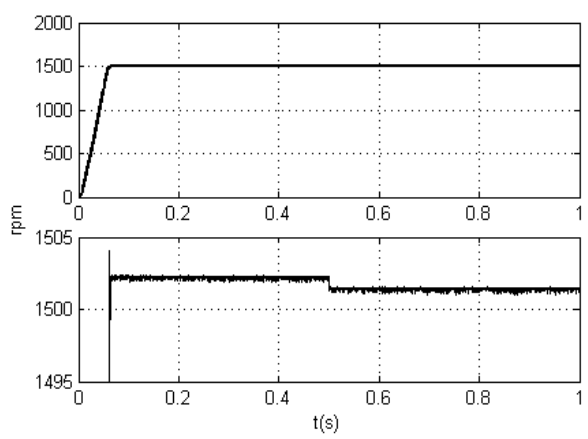

(a)

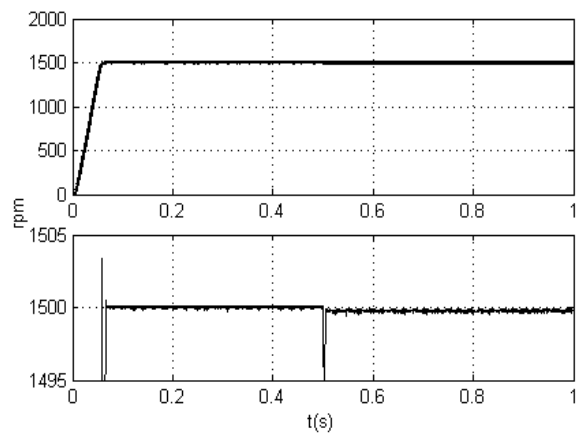

(b)

Figure 5. Speed curves of motor at $1500 \mathrm{rpm}$
a) C-DTC
b) FLSVM-DTC 


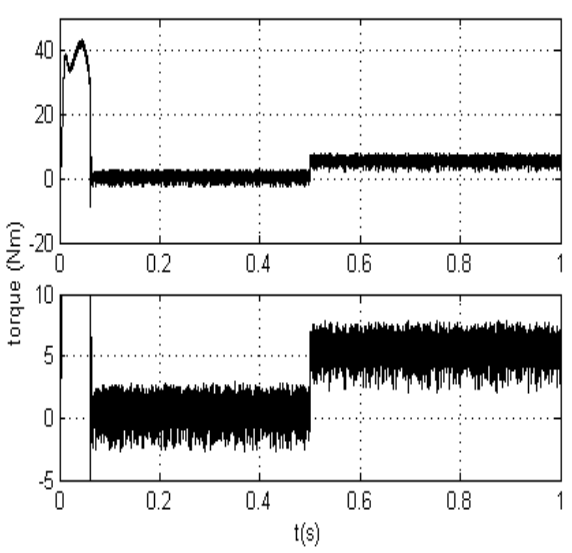

(a)

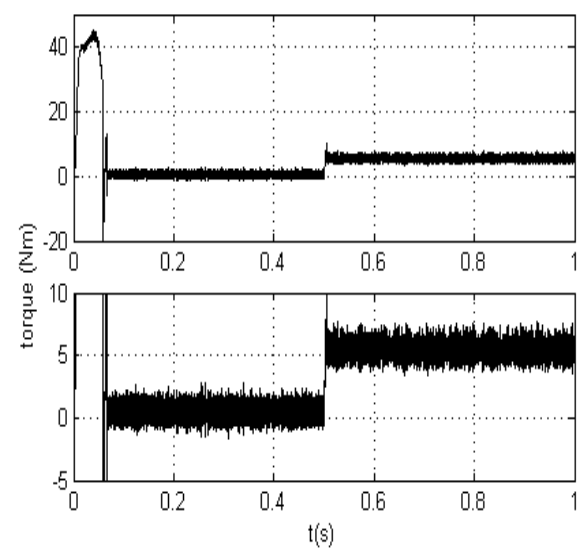

(b)

Figure 6. Torque curves of motor at $1500 \mathrm{rpm}$
a) C-DTC
b) FLSVM-DTC

According to the speed and torque curves which given in Figure 5. and Figure 6., the motor has reached the reference speed at 0,075 . sec. for both control scheme. So, it can be said that there are no difference between C-DTC and FLSVM-DTC and the motor has almost same performance at transient conditions for both control scheme. However, the main differences have appeared at steady state conditions. It can be seen that, with the FLSVM-DTC instantaneous speed fluctuations and torque ripples of the motor are reduced significantly.

In the second step of simulation studies, the motor has been at low speed with two different load conditions. The simulation results of speed and torque responses at $250 \mathrm{rpm}$ reference are shown in Figure 7. and Figure 8., respectively.

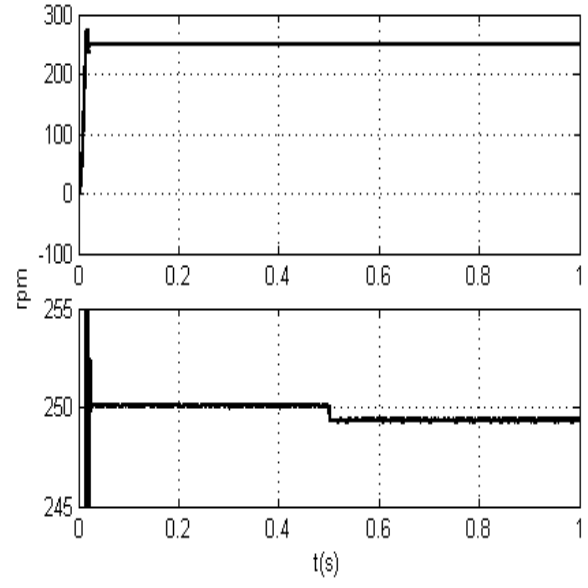

(a)

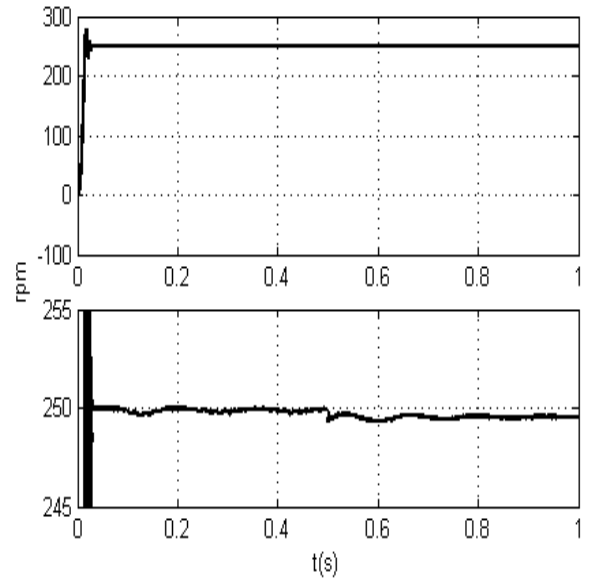

(b)

Figure 7. Speed curves of motor at $250 \mathrm{rpm}$
a) C-DTC
b) FLSVM-DTC 


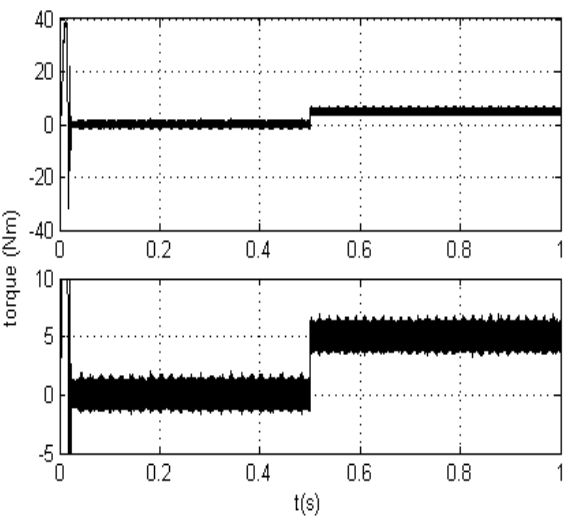

(a)

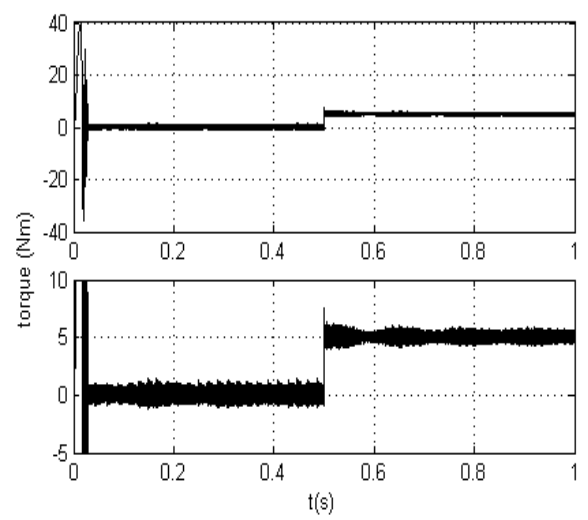

(b)

Figure 8. Torque curves of motor at $250 \mathrm{rpm}$
a) C-DTC
b) FLSVM-DTC

According to the speed and torque curves which given in Figure 7. and Figure 8., the motor has reached the reference speed at 0,02 . sec for both control scheme and still no difference at transient conditions. If we need to compare of steady state conditions of the motor for both control scheme, it must be pointed out that the FLSVM-DTC controlled motor has better performance as lesser torque ripples and speed fluctuations.

\section{Conclusions}

In this paper, a new fuzzy logic based space vector modulation technique has been proposed for direct torque controlled induction motor drives. The numerical simulations have been carried out to verify the proposed technique under different load and speed conditions. The numerical simulations proves that torque and speed responses of the motor are significantly improved with the proposed technique. The torque ripples of the motor are lesser about \% 40, in parallel, the speed fluctuations are reduced according to conventional direct torque control technique. Moreover, the hyseteresis controllers and look-up table that used in conventional scheme are removed. Thus, switching frequency is maintained constant and the complexity of the scheme has been reduced.

\section{REFERENCES}

[1] I. Takahashi and T. Noguchi , "A new quick-response and high efficiency control strategy of an induction motor" IEEE Transactions on Industrial Applications, vol.I A-22 , no.5, pp. 820-827, 1986.

[2] M. Depenbrock, "Direct self control of inverter-fed induction machines" IEEE Transactions in Power Electronics, vol. PE-3, vo. 4, pp. 420-429, 1988.

[3] B. Xu and X. Zhang, "Design of a new Direct Torque Control in induction motor" Control and Decision Conference, (CCDC '09),-- P.5397-5400. 2009.

[4] D. Casadei, G. Serra and A. Tani, "The use of matrix converters in direct torque control of induction machines" IEEE Trans. on Industrial Electronics, vol.48, no.6, pp. 1057-1064, 2001.

[5] Batna University, "Improvement in DTC-SVM of AC Drives Using a New Robust Adaptive Control Algorithm" International Journal of Control, Automation, and Systems, vol. 9, no. 2, pp.267-275, 2011.

[6] D. Casadei, G. Serra and A. Tani, "Implentation of a direct torque control algorithm for induction motors based on discrete space vector modulation" IEEE Trans. on Power Electronics, vol.15, no. 4, pp. 769-777, 2000. 
[7] K.-B. Lee and F. Blaabjerg, "Improved Direct Torque Control for Sensorless Matrix Converter Drives with Constant Switching Frequency and Torque Ripple Reduction” International Journal of Control, Automation, and Systems, vol. 4, no. 1, pp.113-123, 2006.

[8] S. Benaicha, F. Zidani, R.-N. Said, M.-S.-N. Said, “ Direct Torque with Fuzzy Logic Torque Ripple Reduction Based Stator Flux Vector Control" Computer and Electrical Engineering, (ICCEE '09), vol.2, pp. 128-133, 2009.

[9] N. Sadati, S. Kaboli, H. Adeli, E. Hajipour and M. Ferdowsi, "Online Optimal Neuro-Fuzzy Flux Controller for DTC Based Induction Motor Drives" Applied Power Electronics Conference and Exposition (APEC 2009),- P.210-215. 2009.

[10] Z. Tan, Y. Li and Y. Zeng, "A three-level speed sensor-less DTC drive of induction motor based on a full-order flux observer" Power System Technology, Proceedings. PowerCon International Conference, vol. 2, pp. 1054- 1058, 2002.

[11] G. Ya and L. Weiguo, "A new method research of fuzzy DTC based on full-order state observer for stator flux linkage" Computer Science and Automation Engineering (CSAE), 2011 IEEE International Conference, vol. 2, pp.104-108, 2011.

[12] P. Vas, "Sensorless vector and direct torque control" - Oxford University Press, 2003.

[13] Zhenyu Yu "Space-Vector PWM With TMS320C24x/F24x Using Hardware and Software Determined Switching Patterns" Texas Ins. Application Report, SPRA524, pp. 5., 1999.

\section{Authors}

Fatih Korkmaz was born in Kırıkkale, Turkey, in 1977. He received the B.T., M.S., and Doctorate degrees in in electrical education, from University of Gazi, Turkey, respectively in 2000, 2004 and 2011. His current research field includes Electric Machines Drives and Control Systems

İsmail TOPALOGLU was born in Adana, Turkey, in 1983. He received the B.Sc , M.Sc. and Ph.D degrees in electrical education from University of Gazi in 2007,2009 and 2013, respectively. His current research interests include Computer aided design and analysis of conventional and novel electrical and magnetic circuits of electrical machines, sensors and transducers, mechatronic systems

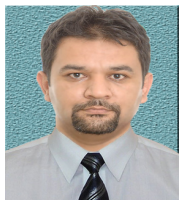

Hayati Mamur was born in Bolu, Turkey, in 1974. He received the B.Sc , M.Sc. and $\mathrm{Ph} . \mathrm{D}$ degrees in electrical education from University of Gazi in 1996,2005 and 2013, respectively. His research interests include automatic control, SCADA, PLC, microcontroller, DSP control applications, renewable energy, and thermoelectric modules.
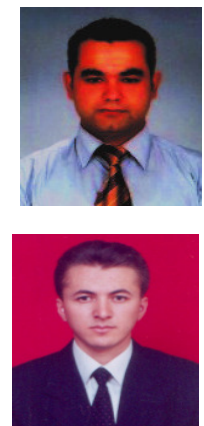